University of New Orleans

ScholarWorks@UNO

$9-19-2007$

\title{
Embedded centrosymmetric multilayer stacks as complete- transmission quarter-wave and half-wave retarders under conditions of frustrated total internal reflection
}

\author{
S. R. Perla \\ R. M.A. Azzam \\ University of New Orleans, razzam@uno.edu
}

Follow this and additional works at: https://scholarworks.uno.edu/ee_facpubs

Part of the Electrical and Electronics Commons

\section{Recommended Citation}

S. R. Perla and R. M. A. Azzam, "Embedded centrosymmetric multilayer stacks as complete-transmission quarter-wave and half-wave retarders under conditions of frustrated total internal reflection," J. Opt. Soc. Am. A 24, 3255-3260 (2007)

This Article is brought to you for free and open access by the Department of Electrical Engineering at ScholarWorks@UNO. It has been accepted for inclusion in Electrical Engineering Faculty Publications by an authorized administrator of ScholarWorks@UNO. For more information, please contact scholarworks@uno.edu. 


\title{
Embedded centrosymmetric multilayer stacks as complete-transmission quarter-wave and half-wave retarders under conditions of frustrated total internal reflection
}

\author{
S. R. Perla and R. M. A. Azzam* \\ Department of Electrical Engineering, University of New Orleans, New Orleans, Louisiana 70148, USA \\ *Corresponding author: rasheed.azzam@gmail.com
}

Received January 19, 2007; revised June 28, 2007; accepted July 9, 2007;

posted July 17, 2007 (Doc. ID 79191); published September 19, 2007

\begin{abstract}
A centrosymmetric multilayer stack of two transparent materials, which is embedded in a high-index prism, can function as a complete-transmission quarter-wave or half-wave retarder (QWR or HWR) under conditions of frustrated total internal reflection. The multilayer consists of a high-index center layer sandwiched between two identical low-index films with high-index-low-index bilayers repeated on both sides of the central trilayer, maintaining the symmetry of the entire stack and constituting a QWR $\left(\Delta_{t}=90^{\circ}\right.$ or $\left.270^{\circ}\right)$ or $\operatorname{HWR}\left(\Delta_{t}=180^{\circ}\right)$ in transmission. A QWR design at wavelength $\lambda=1.55 \mu \mathrm{m}$ is presented that employs an 11-layer stack of Si and $\mathrm{SiO}_{2}$ thin films, which is embedded in a GaP cube prism. The intensity transmittances for the $p$ and $s$ polarizations remain $>99 \%$ and $\Delta_{t}$ deviates from $90^{\circ}$ by $< \pm 3^{\circ}$ over a $100 \mathrm{~nm}$ spectral bandwidth $(1.5 \leqslant \lambda$ $\leqslant 1.6 \mu \mathrm{m}$ ), and by $\leqslant \pm 7^{\circ}$ over an internal field view of $\pm 1^{\circ}$ (incidence angle $44^{\circ} \leqslant \phi_{0} \leqslant 46^{\circ}$ inside the prism). An HWR design at $\lambda=1.55 \mu \mathrm{m}$ employs seven layers of $\mathrm{Si}$ and $\mathrm{SiO}_{2}$ thin films embedded in a Si cube, has an average transmittance $>93 \%$, and $\Delta_{t}$ that differs from $180^{\circ}$ by $< \pm 0.3^{\circ}$ over a $100 \mathrm{~nm}$ bandwidth $(1.5 \leqslant \lambda$ $\leqslant 1.6 \mu \mathrm{m})$ and by $< \pm 17^{\circ}$ over an internal field view of $\pm 1^{\circ}$. The sensitivity of these devices to film-thickness errors is also considered. (C) 2007 Optical Society of America

OCIS codes: $120.2130,260.5430,230.5440$.
\end{abstract}

\section{INTRODUCTION}

Quarter-wave and half-wave retarders (QWR and HWR) are widely used for the control and analysis of polarized light with numerous applications [1,2]. The desired differential phase shift between two orthogonal linear polarizations is commonly obtained when light is transmitted through a natural crystalline or form-birefringent plate or by total internal reflection in the presence or absence of thin films [3-7]. External-reflection retarders that use transparent single or multilayer thin films on highreflectance substrates have also been introduced [8-13].

Transparent multilayer thin films deposited on a transparent substrate can provide QWR in transmission at oblique incidence in air [14]. Ninety-degree transmission differential phase shift is also obtained by using light interference in a tilted bilayer membrane at a high angle of incidence, but with unequal throughput for the $p$ and $s$ polarizations [15]. Transmission multilayer phase retarders in the soft-x-ray region (in which all thin film and substrate materials are absorbing) have also been described $[16,17]$. Finally, circular polarization beam splitters with dual QWR in reflection and transmission have been reported recently that use frustrated total internal reflection (FTIR) by an embedded low-index film or a symmetric trilayer $[18,19]$.

In this paper we demonstrate that a QWR or HWR can be achieved by using near-complete optical tunneling of both $p$ and $s$-polarized light at oblique incidence by means of a transparent centrosymmetric multilayer stack, which is embedded in a high-index prism, with good spectral response (over a $100 \mathrm{~nm}$ bandwidth in the near IR) and limited angular sensitivity.

The design procedure is outlined in Section 2. Spectral, angular, and film-thickness sensitivity of QWR and HWR that use centrosymmetric stacks of $\mathrm{SiO}_{2}-\mathrm{Si}$ thin films embedded in a high-index prism are considered in Sections 3 and 4 , respectively. Section 5 gives a brief summary of the paper.

\section{DESIGN PROCEDURE}

Consider a centrosymmetric multilayer stack, Fig. 1, which consists of a central symmetric trilayer structure (center layer of high refractive index $n_{2}$ and normalized thickness $z_{2}$, sandwiched between two identical thin films of low refractive index $n_{1}$ and normalized thickness $z_{1}$ ) and low-index $\left(n_{1}\right)$-high-index $\left(n_{2}\right)$ bilayers that are repeated symmetrically on both sides of the central unit. The entire multilayer stack is embedded in a high-index prism of refractive index $n_{0}$. The normalized thickness $z_{i}$ of the $i$ th film is defined by

$$
z_{i}=d_{i} / D_{i},
$$

where $d_{i}$ is the metric film thickness, and 


$$
D_{i}=\lambda / 4 n_{i}, \quad i=1,2,3, \ldots, m,
$$

is the quarter-wave film thickness at normal incidence, $\lambda$ is the vacuum wavelength of light, and $m$ is the odd num-

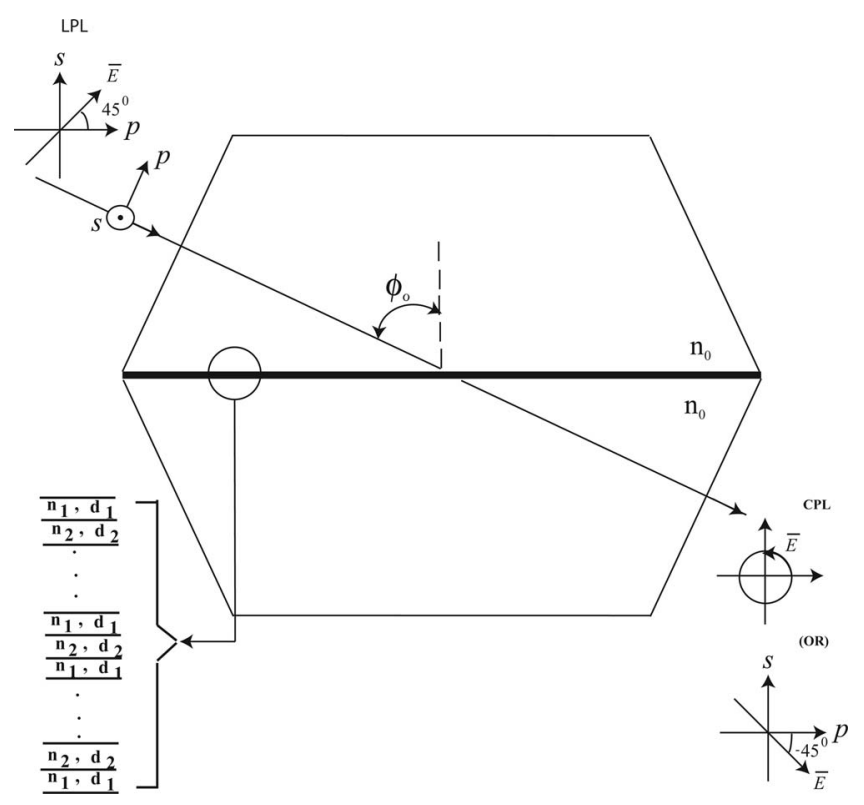

Fig. 1. Embedded multilayer thin-film transmission device that operates under conditions of FTIR. $p$ and $s$ are the linear polarizations parallel and perpendicular to the plane of incidence, respectively, and $\phi_{0}$ is the angle of incidence. This near-completetransmission QWR or HWR transforms incident linearly polarized light (LPL) at $45^{\circ}$ azimuth into circularly polarized light (CPL) or linearly polarized light at $-45^{\circ}$ azimuth, respectively, depending on the parameters of the multilayer stack and angle of incidence.
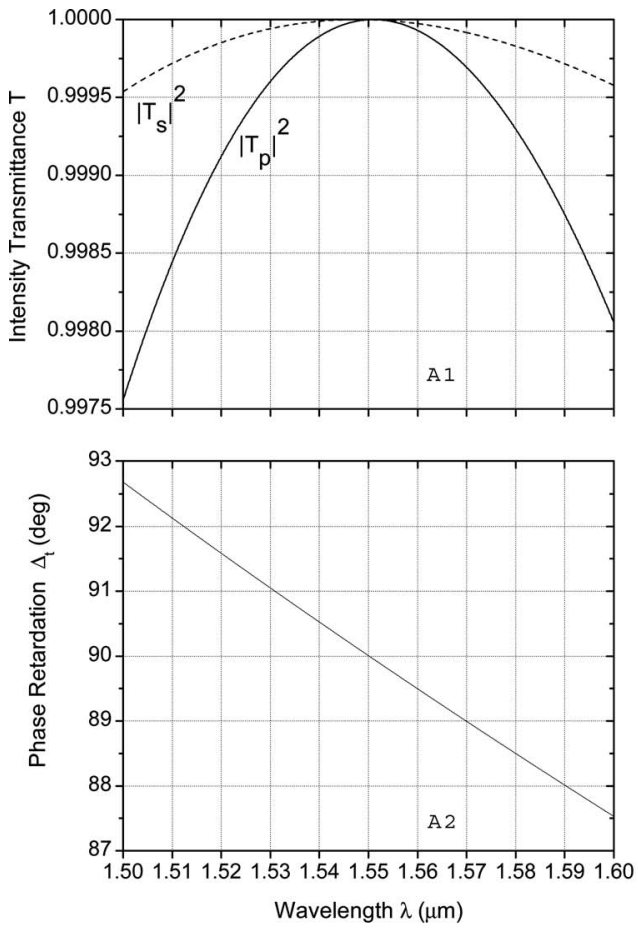

ber of layers. All media are assumed to be homogeneous, transparent, optically isotropic, and separated by parallel-plane boundaries.

The complex-amplitude transmission and reflection coefficients $T_{\nu}$ and $R_{\nu}(\nu=p, s)$ of the multilayer stack for the $p$ and $s$ polarizations at an internal angle of incidence $\phi_{0}$ are determined by the scattering matrix method [20]. Given an all-transparent structure, the condition

$$
\left|R_{\nu}\right|^{2}+\left|T_{\nu}\right|^{2}=1, \quad \nu=p, s,
$$

is satisfied. To achieve a QWR and HWR with essentially complete transmission for the $p$ and $s$ polarizations, the equations

$$
\begin{gathered}
T_{p} \pm j T_{s}=0 \quad(\mathrm{QWR}), \\
T_{p}+T_{s}=0 \quad(\mathrm{HWR})
\end{gathered}
$$

are solved numerically by iteration on the film thicknesses subject to the constraint that

$$
\left|R_{p}\right|^{2}=\left|R_{s}\right|^{2} \approx 0
$$

In our thin-film optics calculations we follow the $\mathrm{Ne}$ braska (Muller) conventions [21]. In evaluating the Fresnel interface reflection coefficients for the $p$ and $s$ polarizations and the complex exponential functions of film thickness, only physically meaningful square roots should be selected to avoid erroneous results [22,23].
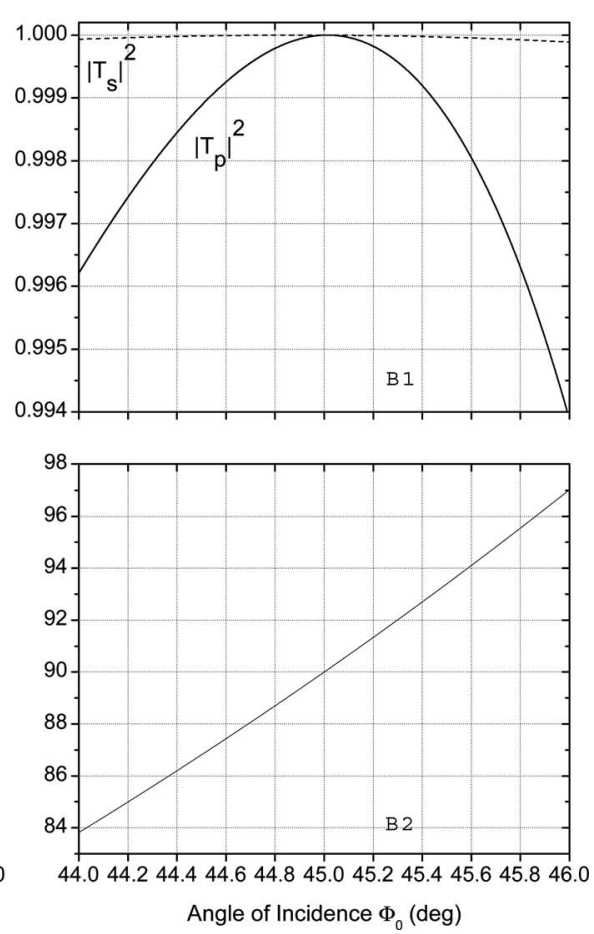

Fig. 2. Panels A1, A2 and B1, B2 show the spectral and angular sensitivities, respectively, of a QWR cube design that operates at $\lambda$ $=1.55 \mu \mathrm{m}$ and $\phi_{0}=45^{\circ}$. The design uses an 11-layer stack of $\mathrm{Si}\left(n_{0}=3.4777\right)$ and $\mathrm{SiO}_{2}\left(n_{1}=1.4444\right)$ thin films embedded in a high-index $\mathrm{GaP}\left(n_{2}=3.0535\right)$ prism. The thicknesses of the $\mathrm{SiO}_{2}$ and $\mathrm{Si}$ thin films are 17.5 and $67.1 \mathrm{~nm}$, respectively. Both the $p$ and $s$ transmittances $\left|T_{p}\right|^{2}$ and $\left|T_{s}\right|^{2}$ and the differential transmission phase shift $\Delta_{t}$ are represented. 


\section{INFRARED QUARTER-WAVE RETARDER USING EMBEDDED $\mathrm{SiO}_{2}-\mathrm{Si}$ MULTILAYER STACK IN GaP PRISM}

A specific QWR cube design $\left(\phi_{0}=45^{\circ}\right)$ at the light-wave communications wavelength of $\lambda=1.55 \mu \mathrm{m}$ uses an 11layer centrosymmetric stack of $\mathrm{Si}\left(n_{2}=3.4777\right)$ and $\mathrm{SiO}_{2}$ $\left(n_{1}=1.4444\right)$ thin films embedded in a high-index $\mathrm{GaP}$ $\left(n_{0}=3.0535\right)$ prism. (The refractive indices of $\mathrm{GaP}$ and $\mathrm{Si}$ are calculated to four decimal places by using published dispersion relations [24]; those of $\mathrm{SiO}_{2}$ are obtained from [25].) The angle of incidence $\left(\phi_{0}=45^{\circ}\right)$ is above the critical angle of the $0-1$ interface $\left(\phi_{\text {crit }}=28.23^{\circ}\right)$, so that FTIR takes place. The solution that we obtain for the normalized and metric film thicknesses is

$$
\begin{gathered}
\left(z_{1}, z_{2}\right)=(0.0651,0.6019), \\
\left(d_{1}, d_{2}\right)=(17.5,67.1) \mathrm{nm} .
\end{gathered}
$$

With these design parameters we calculate $\left|T_{p}\right|^{2}=\left|T_{s}\right|^{2}$ $=0.9999$ and $\Delta_{t}=90.00^{\circ}$.

It is of interest to consider the spectral and angular sensitivities of the above QWR design. For the spectral sensitivity, the film thicknesses $d_{1}=17.5 \mathrm{~nm}, d_{2}$ $=67.1 \mathrm{~nm}$ and the angle of incidence $\phi_{0}=45^{\circ}$ are kept constant, and the wavelength $\lambda$ is scanned over a $100 \mathrm{~nm}$ range from 1.5 to $1.6 \mu \mathrm{m}$. The dispersion of all materials in this spectral region is accounted for [24,25]. For the angle sensitivity, the film thicknesses $d_{1}=17.5 \mathrm{~nm}, d_{2}$ $=67.1 \mathrm{~nm}$ and the wavelength $\lambda=1.55 \mu \mathrm{m}$ are kept constant, and the internal angle of incidence $\phi_{0}$ is varied by $\pm 1^{\circ}$.
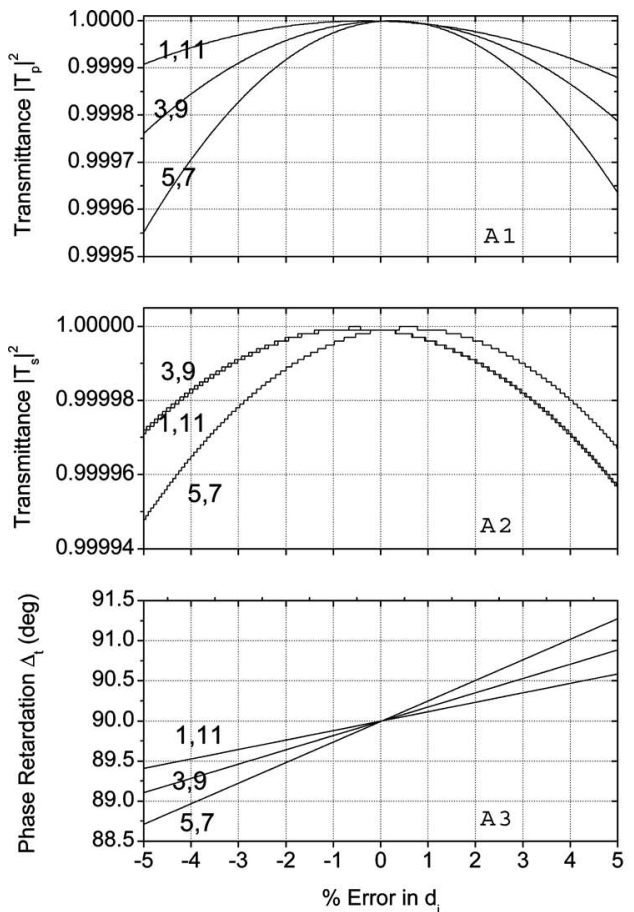

Panel A1 of Fig. 2 shows that $\left|T_{p}\right|^{2}$ and $\left|T_{s}\right|^{2}$ remain $>99.75 \%$ over the $100 \mathrm{~nm}$ spectral region with a locally flat maximum (100\% transmission) at the design wavelength $\lambda=1.55 \mu \mathrm{m}$; hence the amplitude diattenuation in transmission is $<0.2 \%$. Panel A2 of Fig. 2 shows that the differential phase shift $\Delta_{t}$ deviates from $90^{\circ}$ by $< \pm 3^{\circ}$ over the $100 \mathrm{~nm}$ spectral range. Panels B1 and B2 of Fig. 2 show $\left|T_{p}\right|^{2},\left|T_{s}\right|^{2}$, and $\Delta_{t}$ as functions of the angle of incidence $\phi_{0} \cdot\left|T_{p}\right|^{2}$ and $\left|T_{s}\right|^{2}$ remain high $(>99.4 \%)$, while $\Delta_{t}$ deviates from $90^{\circ}$ by $< \pm 7^{\circ}$ for $\pm 1^{\circ}$ change in the internal angle of incidence around $\phi_{0}=45^{\circ}$. Note, however, that the field of view of the QWR in air is wider (by a factor of $\approx 3$ ) if light refraction from air to $\mathrm{GaP}$ at the entrance face of the prism is accounted for by using Snell's law.

We now consider the sensitivity of this QWR to filmthickness errors by keeping the wavelength $\lambda=1.55 \mu \mathrm{m}$ and angle of incidence $\phi_{0}=45^{\circ}$ constant and varying the thickness $d_{i}$ of the $i$ th film $(i=1,2, \ldots, 11)$ by $\pm 5 \%$ around its design value. (The layers are numbered starting from the film adjacent to the medium of incidence.) The resulting small shifts in the transmittances $\left|T_{p}\right|^{2}$ and $\left|T_{s}\right|^{2}$ (which are parabolic) and in the differential phase shift $\Delta_{t}$ (which are linear) are represented in Fig. 3. The left Panels A1, A2, and A3 of Fig. 3 show the effect of thickness errors of the odd-numbered low-index $\left(\mathrm{SiO}_{2}\right)$ films, whereas the right Panels B1, B2, and B3 show the effect of errors in thickness of the even-numbered high-index (Si) films. Because of the symmetry of the design stack, thickness errors for films that are symmetrically located above and below the center layer (e.g., 1 and 11, 2 and 10, and 3 and 9) produce identical shifts in the retarder's response. The effect of simultaneous errors of thickness of
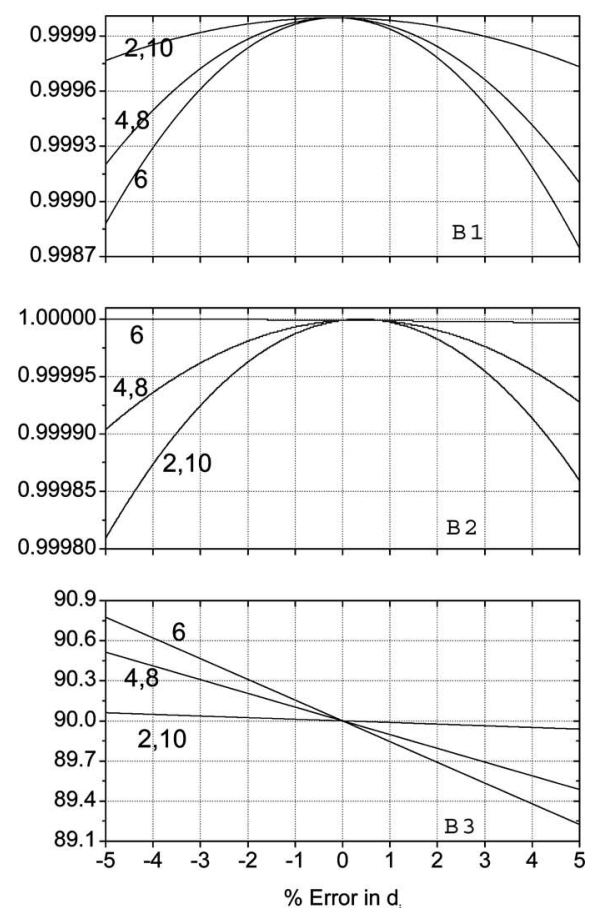

Fig. 3. Panels A1, A2, A3 and B1, B2, B3 show the sensitivities of the QWR cube design that operates at $\lambda=1.55 \mu \mathrm{m}$ and $\phi_{0}=45^{\circ}$ to errors of thickness of the odd- and even-numbered films, respectively. Both the $p$ and $s$ transmittances $\left|T_{p}\right|^{2}$ and $\left|T_{s}\right|^{2}$ and the differential transmission phase shift $\Delta_{t}$ are represented in this figure. The design uses an 11-layer stack of $\mathrm{Si}\left(n_{2}=3.4777\right)$ and $\mathrm{SiO}_{2}\left(n_{1}=1.4444\right)$ thin films embedded in a high-index $\mathrm{GaP}\left(n_{0}=3.0535\right)$ prism. The thicknesses of the $\mathrm{SiO}_{2}$ and $\mathrm{Si}$ thin films are changed by $\pm 5 \%$ around the design values of 17.5 and $67.1 \mathrm{~nm}$, respectively. 

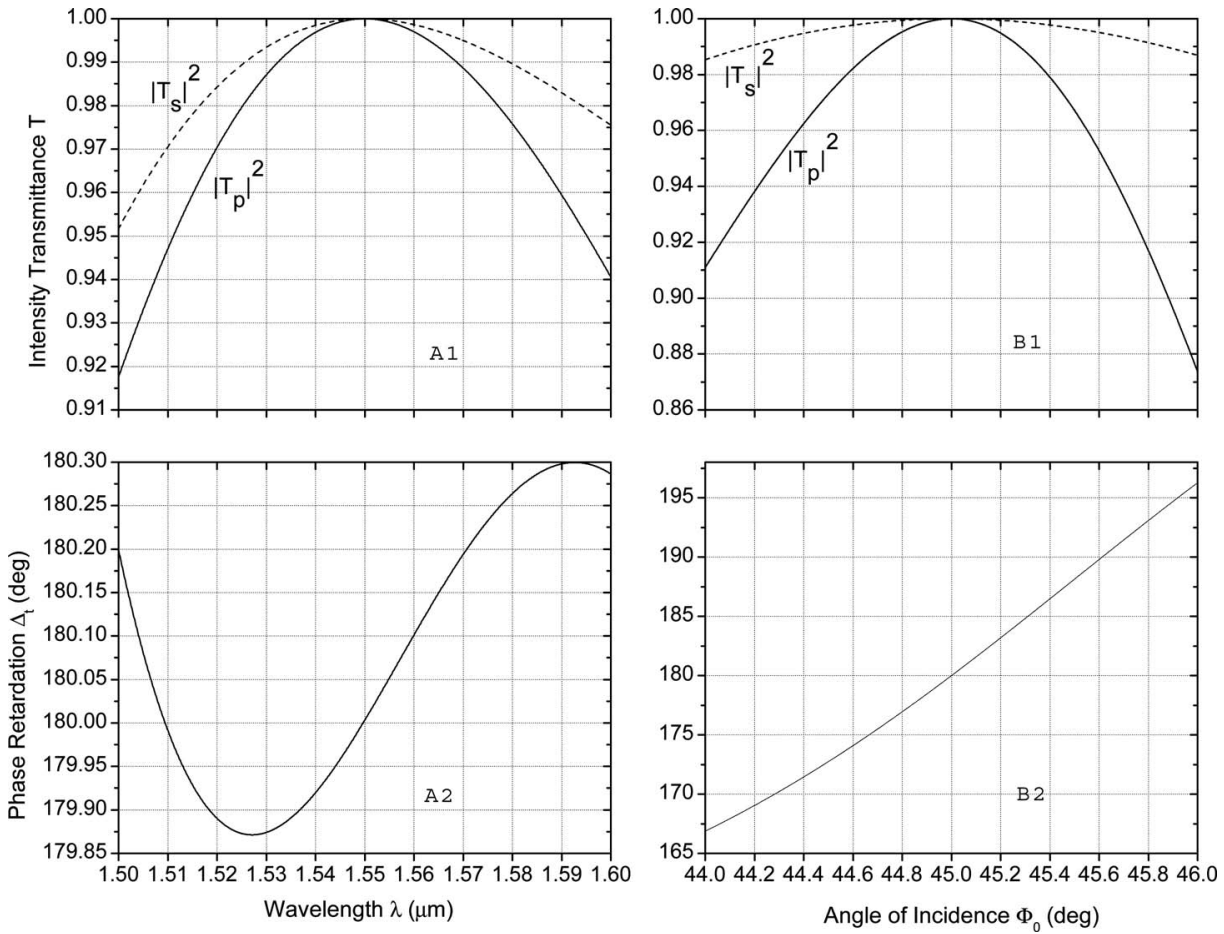

Fig. 4. Panels A1, A2 and B1, B2 show the spectral and angular sensitivities, respectively, of an HWR cube design that operates at $\lambda$ $=1.55 \mu \mathrm{m}$ and $\phi_{0}=45^{\circ}$ and that uses a centrosymmetric seven-layer stack of $\mathrm{Si}\left(n_{2}=3.4777\right)$ and $\mathrm{SiO}_{2}\left(n_{1}=1.4444\right)$ thin films embedded in a $\mathrm{Si}$ prism $\left(n_{0}=3.4777\right)$. The design thicknesses of the $\mathrm{SiO}_{2}$ and $\mathrm{Si}$ thin films are $44.0 \mathrm{~nm}$ and $d_{2}=223.0 \mathrm{~nm}$, respectively. Both the $p$ and $s$ transmittances $\left|T_{p}\right|^{2}$ and $\left|T_{s}\right|^{2}$ and the differential transmission phase shift $\Delta_{t}$ are represented.

all films can be determined, to first order in retardance or second order in transmittance, by superposition using the results shown in Fig. 3.

\section{INFRARED HALF-WAVE RETARDER USING EMBEDDED $\mathrm{SiO}_{2}-\mathrm{Si}$ MULTILAYER STACK IN Si PRISM}

An HWR cube design at $\lambda=1.55 \mu \mathrm{m}$ uses a centrosymmetric seven-layer stack of $\mathrm{Si}\left(n_{2}=3.4777\right)$ and $\mathrm{SiO}_{2}\left(n_{1}\right.$ $=1.4444)$ thin films embedded in a high-index $\mathrm{Si}\left(n_{0}\right.$ $=3.4777$ ) prism. (Bulk and thin-film Si are assumed to have the same refractive index.) The angle of incidence $\left(\phi_{0}=45^{\circ}\right)$ is above the critical angle of the $0-1$ interface $\left(\phi_{\text {crit }}=24.54^{\circ}\right)$; hence FTIR takes place. The solution for the normalized and metric film thicknesses is

$$
\begin{gathered}
\left(z_{1}, z_{2}\right)=(0.1641,2.0013) \\
\left(d_{1}, d_{2}\right)=(44.0,223.0) \mathrm{nm} .
\end{gathered}
$$

With these design parameters we achieve $\left|T_{p}\right|^{2}=\left|T_{s}\right|^{2}$ $=0.9999$ and $\Delta_{t}=179.98^{\circ}$.

Figure 4 shows the spectral and angular sensitivities of the HWR design. The dispersion of $\mathrm{Si}$ and $\mathrm{SiO}_{2}$ in the $100 \mathrm{~nm}$ spectral region is accounted for [24,25]. Panel A1 of Fig. 4 shows that $\left|T_{p}\right|^{2}$ and $\left|T_{s}\right|^{2}$ remain $>91 \%$ over the $100 \mathrm{~nm}$ spectral region with a locally flat maximum $(=100 \%)$ at the design wavelength $\lambda=1.55 \mu \mathrm{m}$. The amplitude diattenuation is $<3 \%$. Panel A2 of Fig. 4 shows that $\Delta_{t}$ deviates from $180^{\circ}$ by $\leqslant \pm 0.3^{\circ}$ over the $100 \mathrm{~nm}$ spectral range. Panels $\mathrm{B} 1$ and $\mathrm{B} 2$ of Fig. 4 show $\left|T_{p}\right|^{2}$, $\left|T_{s}\right|^{2}$, and $\Delta_{t}$ as functions of $\phi_{0}$. $\left|T_{s}\right|^{2}$ remains high
(>98\%), whereas $\left|T_{p}\right|^{2}$ dips to $87.5 \%$, as the angle of incidence is changed by $\pm 1^{\circ}$. The differential transmission phase shift $\Delta_{t}$ deviates from $180^{\circ}$ by $< \pm 17^{\circ}(<10 \%)$ for $\pm 1^{\circ}$ change in the internal angle of incidence around $\phi_{0}$ $=45^{\circ}$. The field of view of the HWR in air is wider (by a factor of $\approx 3.5$ ) if the refraction of light from air to $\mathrm{Si}$ at the entrance face of the prism is accounted for.

The sensitivity of this HWR design to film-thickness errors is considered by holding the wavelength $\lambda=1.55 \mu \mathrm{m}$ and angle of incidence $\phi_{0}=45^{\circ}$ constant and by varying each film thickness $d_{i}(i=1,2, \ldots, 7)$ by $\pm 5 \%$ around its design values. The resulting shifts in the transmittances $\left|T_{p}\right|^{2}$ and $\left|T_{s}\right|^{2}$ (which are parabolic) are represented by panels A1 and B1 of Fig. 5, and the corresponding shifts in the differential phase shift $\Delta_{t}$ (which are linear) are shown in panels A2 and B2 of Fig. 5. Given the symmetry of the design stack, errors of thickness of films that are symmetrically located on opposite sides of the center layer produce identical effects. The result of introducing simultaneous errors in the thicknesses of all films can be determined, to first order in retardance and second order in transmittance, by superposition using the results shown in Fig. 5.

\section{SUMMARY}

We have demonstrated that optical tunneling by an embedded centrosymmetric multilayer structure under FTIR conditions can achieve a QWR or HWR with nearcomplete transmission for $p$ - and $s$-polarized light and with good spectral response and limited angular sensitivity. The sensitivity of these devices to film-thickness errors is also considered. 

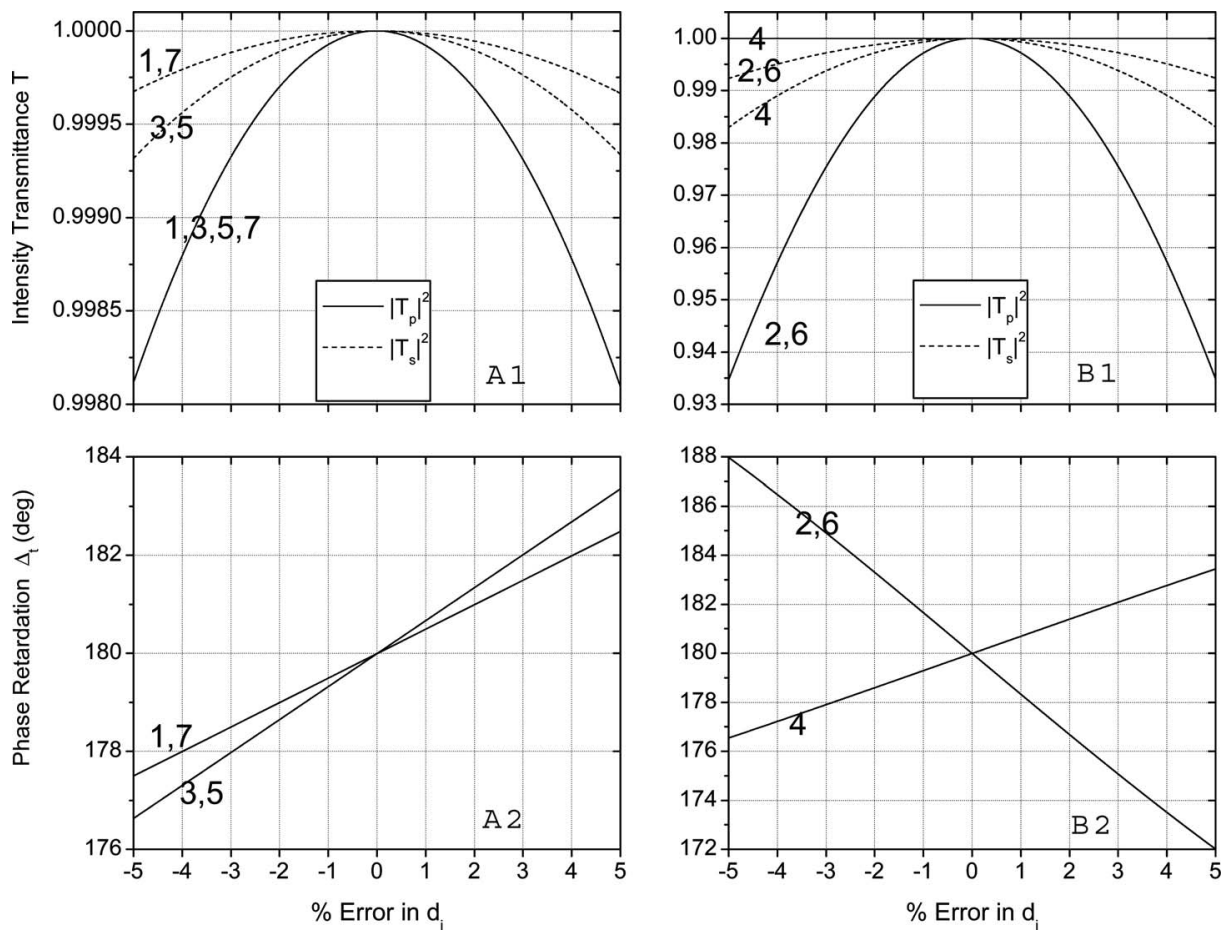

Fig. 5. Transmittances $\left|T_{p}\right|^{2}$ and $\left|T_{s}\right|^{2}$ for $p$ - and $s$-polarized light and differential transmission phase shift $\Delta_{t}$ of an HWR cube design, which operates at $\lambda=1.55 \mu \mathrm{m}$ and $\phi_{0}=45^{\circ}$, are plotted versus the error of thickness of each film. The design uses a seven-layer stack of $\mathrm{Si}\left(n_{2}=3.4777\right)$ and $\mathrm{SiO}_{2}\left(n_{1}=1.4444\right)$ thin films embedded in a high-index $\mathrm{Si}\left(n_{0}=3.4777\right)$ prism. The thicknesses of the $\mathrm{SiO}{ }_{2}$ and $\mathrm{Si}$ thin films are changed by $\pm 5 \%$ around the design values of 44.0 and $223.0 \mathrm{~nm}$, respectively.

Both total internal reflection at interfaces and light interference in thin films play a role in making these devices possible. It is also the combination of these effects that has made a new class of high-performance polarizing beam splitters possible [26,27]. In general, we find a trade-off between the requirements of attaining a good spectral response and that of attaining a good angular response. For example, quasi-monochromatic QWR and HWR designs with a significantly improved field of view are obtained that are not reported here.

\section{REFERENCES}

1. R. M. A. Azzam and N. M. Bashara, Elliposmetry and Polarized Light (North-Holland, 1987).

2. D. Clarke and J. F. Grainger, Polarized Light and Optical Measurement (Pergamon, 1971).

3. J. M. Bennett, "A critical evaluation of rhomb-type quarterwave retarders," Appl. Opt. 9, 2123-2129 (1970).

4. R. M. A. Azzam and C. L. Spinu, "Achromatic angleinsensitive infrared quarter-wave retarder based on total internal reflection at the $\mathrm{Si}-\mathrm{SiO}_{2}$ interface," J. Opt. Soc. Am. A 21, 2019-2022 (2004).

5. E. Spiller, "Totally reflecting thin-film phase retarders," Appl. Opt. 23, 3544-3549 (1984).

6. E. Cojocaru, R. Dabu, V. Draganescu, T. Julea, and F. Nichitiu, "Achromatic thin-film totally reflecting quarterwave retarders," Appl. Opt. 28, 211-212 (1989).

7. E. Cojocaru, T. Julea, and F. Nichitiu, "Infrared thin-film totally reflecting quarter-wave retarders," Appl. Opt. 30, 4124-4125 (1991).

8. A.-R. M. Zaghloul, R. M. A. Azzam, and N. M. Bashara, "An angle-of-incidence-tunable $\quad \mathrm{SiO}_{2}-\mathrm{Si} \quad$ (film-substrate) reflection retarder for the UV mercury line $\lambda=2537 \AA$," Opt. Commun. 14, 260-262 (1975).

9. S. Kawabata and M. Suzuki, " $\mathrm{MgF}_{2}-\mathrm{Ag}$ tunable reflection retrader," Appl. Opt. 19, 484-486 (1980).
10. R. M. A. Azzam and B. E. Perilloux, "Constraint on the optical constants of a film-substrate system for operation as an external-reflection retarder at a given angle of incidence," Appl. Opt. 24, 1171-1179 (1985).

11. W. H. Southwell, "Multilayer coating design achieving a broadband $90^{\circ}$ phase shift," Appl. Opt. 19, 2688-2692 (1980).

12. J. H. Apfel, "Graphical method to design multilayer phase retarders," Appl. Opt. 20, 1024-1029 (1981).

13. M. M. K. Howlader and R. M. A. Azzam, "Periodic and quasiperiodic nonquarterwave multilayer coatings for 90-deg reflection phase retardance at 45-deg angle of incidence," Opt. Eng. 34, 869-875 (1995).

14. W. H. Southwell, "Thin film transmissive phase retarders," in Proceedings of International Conference on Lasers, C. B. Collins, ed. (STS, 1981), pp. 578-585.

15. R. M. A. Azzam and F. A. Mahmoud, "Tilted bilayer membranes as simple transmission quarter-wave retardation plates," J. Opt. Soc. Am. A 18, 421-425 (2001).

16. J. B. Kortright, M. Rice, and K. D. Franck, "Tunable multilayer EUV/soft x-ray polarimeter," Rev. Sci. Instrum. 66, 1567-1569 (1995).

17. D.-E. Kim, S.-M. Lee, and I. Jeon, "Transmission characteristics of multilayer structure in the soft x-ray region and its application to the design of quarter-wave plates at 13 and $4.4 \mathrm{~nm}$," J. Vac. Sci. Technol. A 17, 398-402 (1999).

18. R. M. A. Azzam and A. De, "Circular polarization beam splitter that uses frustrated total internal reflection by an embedded symmetric achiral multilayer coating," Opt. Lett. 28, 355-357 (2003).

19. R. M. A. Azzam and C. L. Spinu, "Linear-to-circular polarization transformation upon optical tunneling through an embedded low-index film," Opt. Lett. 30, 3183-3185 (2005).

20. Ref. [1], Chap. 4

21. R. H. Muller, "Definitions and conventions in ellipsometry," Surf. Sci. 16, 14-33 (1996).

22. E. Spiller, "Phase conventions in thin film optics and ellipsometry," Appl. Opt. 23, 3036-3037 (1984). 
23. A. M. Kan'an and R. M. A. Azzam, "In-line quarter-wave retarders for the infrared using total refraction and total internal reflection in a prism," Opt. Eng. 33, 2029-2033 (1994).

24. W. J. Tropf, M. E. Thomas, and T. J. Harris, in Handbook of Optics, M. Bass, E. W. Van Stryland, D. R. Williams, and W. L. Wolfe, eds. (McGraw Hill, 1995), Vol. II, Chap. 33.

25. M. Herzberger and C. D. Salzberg, "Refractive indices of infrared optical materials and color correction of infrared lenses," J. Opt. Soc. Am. 52, 420-425 (1962).

26. L. Li and J. A. Dobrowolski, "High-performance thin film polarizing beam splitter operating at angles greater than the critical angle," Appl. Opt. 39, 2754-2771 (2000).

27. S. R. Perla and R. M. A. Azzam, "Wide-angle, highextinction-ratio, infrared polarizing beam splitters using frustrated total internal reflection by an embedded centrosymmetric multilayer," Appl. Opt. 46, 4604-4612 (2007). 